\title{
jAgeDisplay: software for evaluation of data distributions in U-Th-Pb geochronology
}

\author{
Tonny B. Thomsen, Tjerk Heijboer and Pierpaolo Guarnieri
}

During the past $10-15$ years, analytical innovations in geochronology have greatly enhanced the application of geochronological data to geological problems. The advances are mainly driven by developments in laser ablation inductively coupled plasma mass spectrometry (LA-ICPMS) which allows for rapid determination of U-Th-Pb ages of mineral grains in large sample sets. LA-ICPMS has now become the most common tool in the application of zircon geochronology to a host of different geological problems.

One of the most regularly used approaches to evaluate complex U-Th- $\mathrm{Pb}$ geochronological data populations is to use a diagram that combines a binned frequency histogram and a probability density distribution plot (PDP), as described by Sircombe (2004) and Ludwig (2003). This type of diagram is particularly common in sedimentary prov- enance studies using large sets of age data (Morton et al. 1996; Pell et al. 1997; Rainbird et al. 1997; Sircombe 1999; Fergusson et al. 2001). It is also useful for the analysis of complex age patterns in metamorphic and igneous rocks. The Microsoft Excel workbook AgeDisplay (Sircombe 2004) has often been used to produce these diagrams but it is not supported by versions of Excel that are newer than 2003. Stand-alone software for PC written in Java was therefore developed by the Geological Survey of Denmark and Greenland (GEUS). It is based on the same formulae as described in Sircombe (2004), thus the name jAgeDisplay (with $\mathrm{j}$ for Java), and has additional features and graphic improvements. Here we present the setup, operation and capability of the software with examples from single-grain $\mathrm{U} / \mathrm{Pb}$ age data obtained by LA-ICPMS spot analysis.

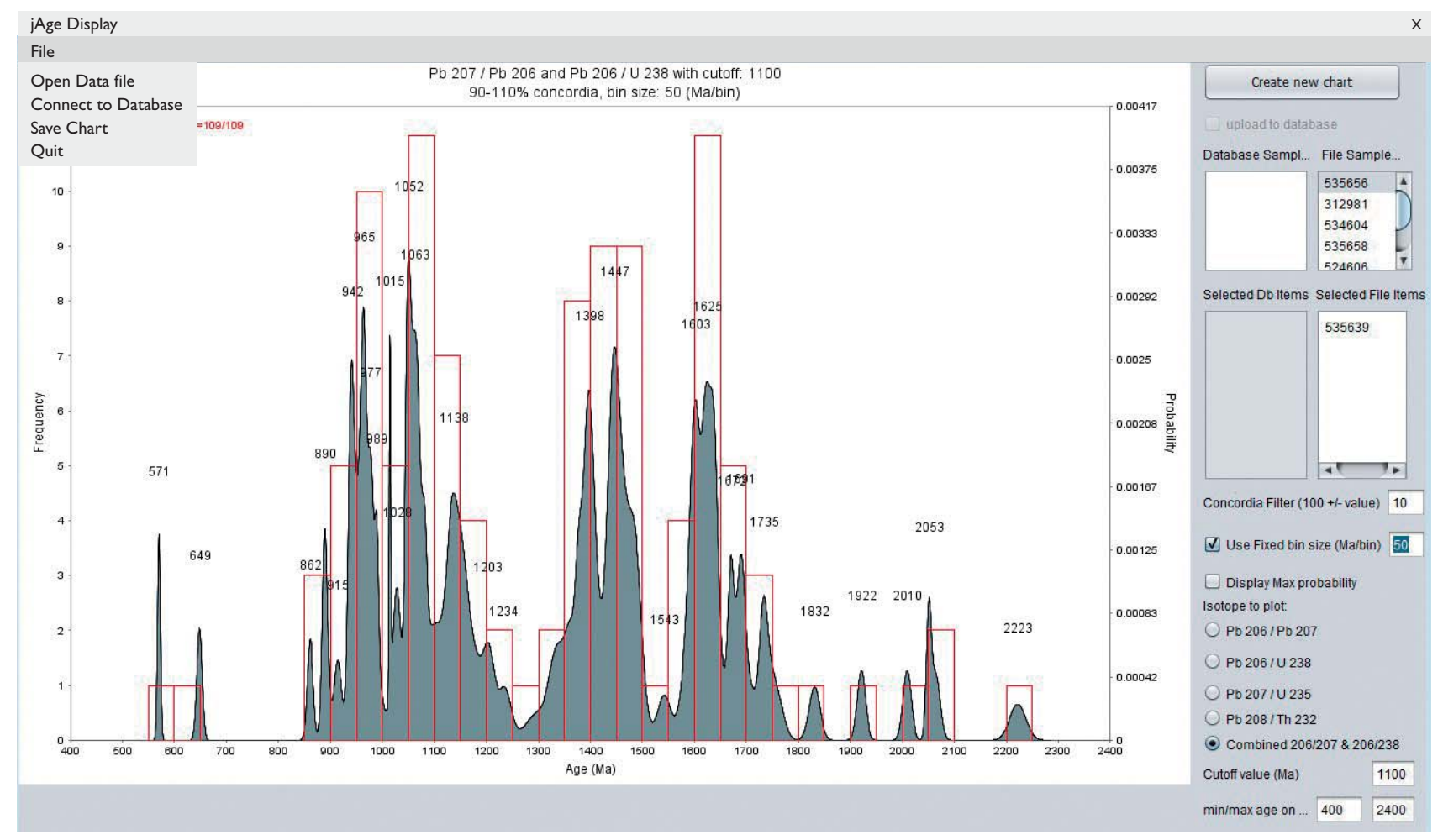

Fig.1. Combined 400-2400 Ma histogram and PDP chart with calculated maximum probability ages for distinct distribution peaks of zircon populations from a single sample, using coupled ${ }^{206} \mathrm{~Pb} /{ }^{238} \mathrm{U}$ and ${ }^{207} \mathrm{~Pb} /{ }^{206} \mathrm{~Pb}$ age pairs. A crossover age of $1100 \mathrm{Ma}$ is used, where ${ }^{206} \mathrm{~Pb} /{ }^{238} \mathrm{U}$ ages and ${ }^{207} \mathrm{~Pb} /{ }^{206} \mathrm{~Pb}$ ages are used below and above this age, respectively. A Fixed bin size of $50 \mathrm{Ma} /$ bin and a Concordia Filter of $\pm 10 \%$ were used. 


\section{Setup and operation of jAgeDisplay}

The jAgeDisplay package (current version 1.0) for PC includes an executable Jar file, a Java MS DOS batch file, a HTML readme file, a brief manual and a folder with test data files. The application is available as shareware from the corresponding author, and it is installed by copying the files you receive to any PC with Java.

jAgeDisplay supports both comma-separated (CSV) and tab-delimited (TAB) input text files, with the same table headers and data types as in AgeDisplay, Iolite (Paton et al. 2011), and GEUS' in-house Zirchron software and database. The input file can include age data from one or more samples, which are loaded from the File menu in the main window (Fig. 1) using the Open Data file option. The input file includes four commonly used radiogenic $\mathrm{U}$ Th- $\mathrm{Pb}$ age pairs, viz. ${ }^{206} \mathrm{~Pb} /{ }^{238} \mathrm{U},{ }^{207} \mathrm{~Pb} /{ }^{235} \mathrm{U},{ }^{207} \mathrm{~Pb} / 206 \mathrm{~Pb}$ and ${ }^{208} \mathrm{~Pb} /{ }^{232} \mathrm{Th}$, together with the sample identification, the name or number of individual analyses, the name of the analytical sequence and information about correction for common lead content. Output charts can be saved in PDF or PNG file format through the Save Chart option in the File menu.

The main window consists of a chart area to the left and the selected sample parameters to the right. When an input file has been loaded, the samples available for plotting are found in the File Samples field or, if loaded from a database, in the Database Samples field. To plot one or more of the loaded samples, they are dragged and dropped in their respective Selected File Items or Selected Db Items fields. The parameters to be used for the chart are selected, and the Create new chart button is pressed.

Combined histograms and probability-density plots for each radiogenic age pair ${ }^{206} \mathrm{~Pb} /{ }^{238} \mathrm{U},{ }^{207} \mathrm{~Pb} /{ }^{235} \mathrm{U},{ }^{207} \mathrm{~Pb} /{ }^{206} \mathrm{~Pb}$, ${ }^{208} \mathrm{~Pb} /{ }^{232} \mathrm{Th}$ ) can be produced. In addition, charts combining the ${ }^{206} \mathrm{~Pb} /{ }^{238} \mathrm{U}$ and ${ }^{207} \mathrm{~Pb} /{ }^{206} \mathrm{~Pb}$ age pairs can be made by manually setting a specific age (denoted Cutoff value) that controls the change from using ${ }^{206} \mathrm{~Pb} /{ }^{238} \mathrm{U}$ ages for the younger age range to ${ }^{207} \mathrm{~Pb} /{ }^{206} \mathrm{~Pb}$ ages for the older age range of the chart (Fig. 1). The frequency in terms of number of analyses for each bin in the histogram is shown on the left $y$-axis, and the calculated probability distribution of zircon ages for the data set on the right $y$-axis. Thus, the probability-density distribution provides an estimate of the true mineral-age distribution for a given rock sample.

The plots can be adjusted by the following parameters:

- Concordia Filter is the maximum allowed discordance (in per cent) for analyses to be considered as concordant, and is determined as $100 \pm$ Set\#Value. This separates the age data used for the plot into two different fields representing 'concordant' and 'discordant' data. In detrital zircon provenance studies a value of $\pm 10 \%$ is often used, where this threshold is used as a measure of the quality of the calculated ages. In contrast to AgeDisplay, the complete data set including the 'discordant' data is not shown behind the 'concordant' data, but separately using the same axis as for the concordant data.

- Use Fixed bin size (Malbin) allows a histogram of filtered ages to be plotted (based on the concordant data obtained via the Concordia Filter), where the bin size in million years $(\mathrm{Ma})$ is manually chosen. If this checkbox is deselected, a calculated value for the bin size is used, based on the formulae in Doane (1985).

- Display Max Probability (checkbox) shows the ages of the calculated probability peaks for the 'concordant' data set.

- Min/Max age controls the age range to be shown in the chart.

Additional parameters can be set through right-clicking on the produced chart, where the title, chart title, axis range, appearance and colours can be modified.

jAgeDisplay can display a single chart for one data set or stacked charts of several data sets (Fig. 2). Stacked charts are useful for comparison of data sets sampled, e.g. at different geographical, stratigraphical or lithological locations in order to identify trends or differences in the age distributions. The stacking follows the order chosen in the Selected File Items (or Selected DB Items) window at the right, and can be rearranged as appropriate. As the purpose of stacking is to compare, the stacked data sets are displayed for the same age range as set by the Min/Max age control.

\section{Use of jAgeDisplay in sedimentary provenance and petrological studies}

Detrital studies typically aim to characterise the age population(s) from a sample by means of a large number of single grain analyses, e.g. obtained by LA-ICPMS. In statistical terms the goal of such studies is to estimate the so-called probability density function that gives the relative likelihood of the different ages in the population (Vermeesch 2012). Zircon is the most common mineral used for detrital studies, but other mineral phases like rutile and titanite are increasingly being employed in order to obtain supplementary information (e.g. Zack et al. 2004; Stendal et al. 2006; Meinhold et al. 2008; Thomsen et al. 2015; 


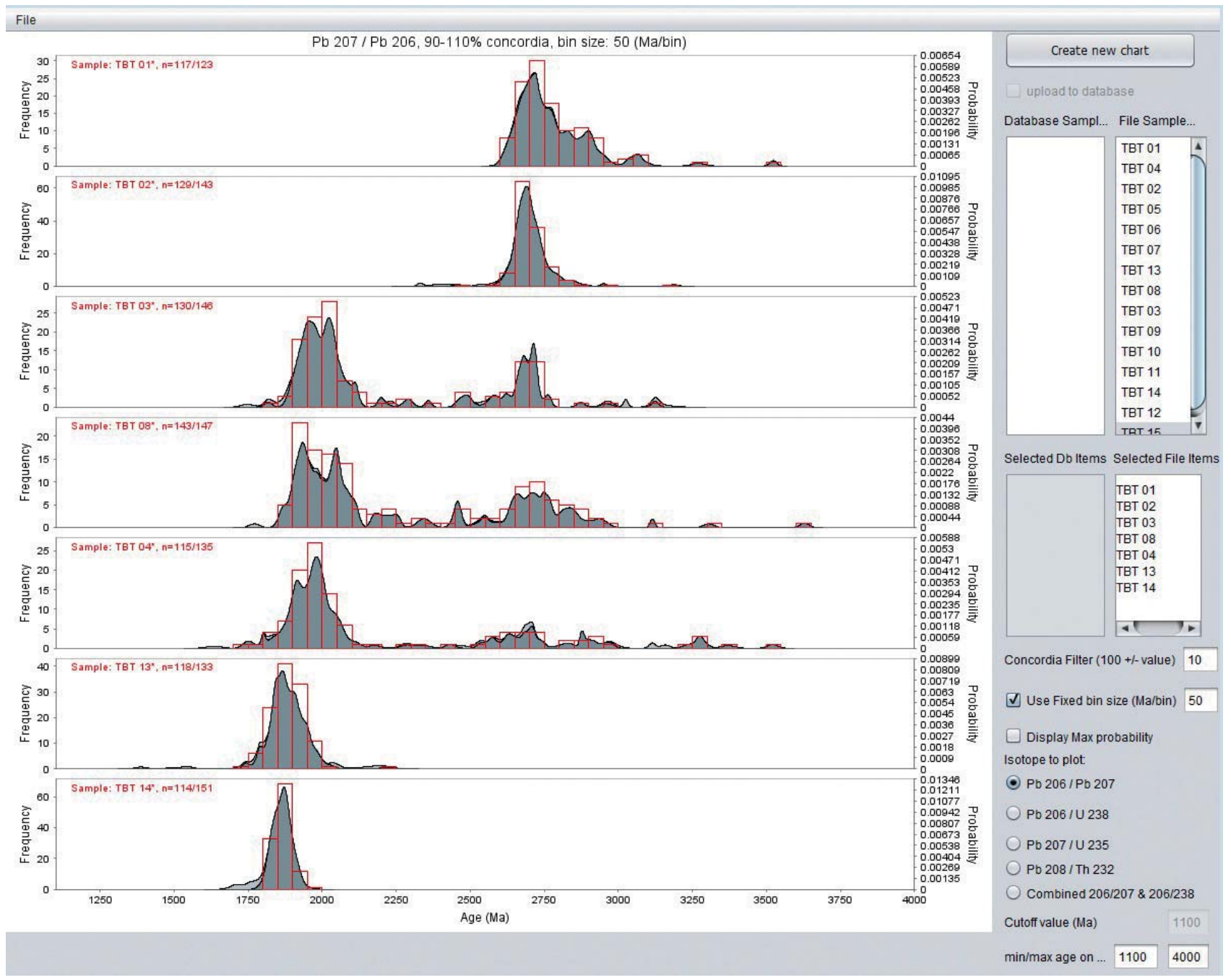

Fig. 2. Stacked chart of combined histograms and PDP charts from 1100 to $4000 \mathrm{Ma}$ of zircons from seven samples using ${ }^{207} \mathrm{~Pb} /{ }^{206} \mathrm{~Pb}$ ages, a Fixed bin size of $50 \mathrm{Ma} /$ bin and a Concordia Filter of $\pm 10 \%$.

Bruand et al. 2016). Signatures of sediment sources not represented in the zircon data set may be present in detrital titanite, rutile or apatite populations. In addition, age data on these minerals may provide further chronological and petrogenetic insight into the tectono-thermal history of their source regions (e.g. McAteer et al. 2010, 2014; Knudsen et al. 2015; Thomsen et al. 2015). Similarily, in metamorphic and magmatic petrology, complex zoning patterns that correspond to distinct geological events can be recorded in zircon, baddeleyite, titanite, rutile, apatite, monazite, xenotime, allanite or any other accessory mineral phase for which the age can be determined by U-Th/ $\mathrm{Pb}$ methods and can be assessed in probability density plots diagrams through the jAgeDisplay software.

\section{Future options in jAgeDisplay}

Although PDPs constitute the most widespread method used today for displaying detrital age distributions, they lack a firm theoretical basis as probability density estimators, and this may produce counter-intuitive results when the number of analyses and/or their quality (precision) is high (Vermeesch 2012). Accordingly, an alternative and robust standard statistical technique, the Kernel Density Estimation (KDE) as described in Vermeesch (2012), will be included in jAgeDisplay, so that users can compare the two methods. We also expect to include a more versatile option for age distribution plots, where any two isotopic pairs can be used in a PDP or KDE diagram, in a similar way as the built-in option for combined ${ }^{206} \mathrm{~Pb} /{ }^{238} \mathrm{U}$ and ${ }^{207} \mathrm{~Pb} / 206 \mathrm{~Pb}$ age distributions. 
Detailed statistics reporting information on the calculated maximum probability peaks can be useful for improved age differentiation of, e.g. magmatic or metamorphic episodes. At present, this information is only indirectly reported through the plot axis. We expect to include this information in pop-up windows for single peaks and as a print-out option including the statistics of all peaks or a chosen age section of the plot.

Finally, the jAgeDisplay software offers an option to load input files from a database through a local server connection (File $=>$ Connect to Database). At present, this option only allows reading of certain data types from GEUS' Oracle server. It is our intention to expand this and thus provide users with access to data from a local server repository.

\section{Additional remark}

In this presentation only $\mathrm{U} / \mathrm{Pb}$ geochronological data obtained by LA-ICPMS analysis on zircon are used. jAgeDisplay can of course also evaluate U-Th-Pb data acquired by other instrumentation and complex age distribution patterns measured from other accessory phases such as titanite, rutile, apatite, monazite, allanite, perovskite, xenotime or other minerals that can incorporate $U$ or Th into their crystal structure.

\section{References}

Bruand, E., Storey, C. \& Fowler, M. 2016: An apatite for progress: Inclusions in zircon and titanite constrain petrogenesis and provenance. Geology 44(2), 91-94, http://dx.doi.org/10.1130/G37301.1

Doane, D.P. 1985: Aesthetic frequency classifications. The American Statistician 30, 181-183.

Fergusson, C.L., Fanning, C.M. \& Green, T.J. 2001: Proterozoic-Cambrian detrital zircon and monazite ages from the Anakie Inlier, central Queensland: Grenville and Pacific-Gondwana signatures. Australian Journal of Earth Sciences 48(6), 857-866.

Knudsen C., Thomsen T.B. \& Hinchey, A. 2015: Detrital zircon, rutile and titanite investigations from present-day Labrador river drainages: fingerprinting the Grenvillean front. Goldschmidt Conference, Prague, 16-21 August 2015. Abstract 1627 only.

Ludwig, K. 2003: User's Manual for Isoplot 3.00: A geochronological toolkit for Microsoft Excel. Berkeley Geochronology Center Special Publication 4, 74 pp.
McAteer, C.A., Daly, J.S., Flowerdew, M.J., Connelly, J.N., Housh, T.B. \& Whitehouse, M.J. 2010: Detrital zircon, detrital titanite and igneous clast $\mathrm{U}-\mathrm{Pb}$ geochronology and basement-cover relationships of the Colonsay Group, SW Scotland: Laurentian provenance and correlation with the Neoproterozoic Dalradian Supergroup. Precambrian Research 181, 21-42.

McAteer, C.A., Daly, J.S., Flowerdew, M.J., Whitehouse, M.J. \& Monaghan, N.M. 2014: Sedimentary provenance, age and possible correlation of the Iona Group, SW Scotland. Scottish Journal of Geology 50, 143-158.

Meinhold, G., Anders, B., Kostopoulos, D. \& Reischmann, T. 2008: Rutile chemistry and thermometry as provenance indicator: an example from Chios Island, Greece. Sedimentary Geology 203, 98-11.

Morton, A.C., Claoué-Long, J.C. \& Berge, C. 1996: SHRIMP constraints on sediment provenance and transport history in the Mesozoic Statfjord Formation, North Sea. Journal of the Geological Society, London 153, 915-929.

Paton, C., Hellstrom, J.C., Paul, P., Woodhead, J.D. \& Hergt, J.M. 2011: Iolite: Freeware for the visualisation and processing of mass spectrometric data. Journal of Analytical Atomic Spectrometry 26(26), 2508-2518.

Pell, S.D., Williams, I.S. \& Chivas, A.R. 1997: The use of protolith zircon-age fingerprints in determining the protosource areas for some Australian dunes sands. Sedimentary Geology 109, 233-260.

Rainbird, R.H., McNicoll, V.J., Theriault, R.J., Heaman, L.M., Abbott, J.G., Long, D.G.F. \& Thorkelson, D.J. 1997: Pan-continental river system draining Grenville orogen recorded by U-Pb and SmNd geochronology of Neoproterozoic quartzarenites and mudrocks, northwestern Canada. Journal of Geology 105, 1-17.

Sircombe, K.N. 1999: Tracing provenance through the isotope ages of littoral and sedimentary detrital zircon, eastern Australia. Sedimentary Geology 124, 47-67.

Sircombe, K.N. 2004: AgeDisplay: an EXCEL workbook to evaluate and display univariate geochronological data using binned frequency histograms and probability density distributions. Computers and Geosciences 30, 21-31.

Stendal, H., Toteu, S.F., Frei, R., Penaye, J., Njel, U.O., Bassahak, J., Nni, J., Kankeu, B., Ngako, V. \& Hell, J.V. 2006: Derivation of detrital rutile in the Yaoundé region from the Neoproterozoic Pan-African belt in southern Cameroon (Central Africa). Journal of African Earth Sciences 4(4), 443-458.

Thomsen, T.B., Knudsen, C. \& Hinchey, A. 2015: Detrital zircon, rutile and titanite investigations from present-day Labrador river drainages: Fingerprinting the Grenvillean front. Geological Survey of Denmark and Greenland Bulletin 33, 77-80.

Vermeesch, P. 2012: On the visualisation of detrital age distributions. Chemical Geology 312-313, 190-194, http://dx.doi.org/10.1016/j. chemgeo.2012.04.021

Zack, T., von Eynatten, H. \& Kronz, A. 2004: Rutile geochemistry and its potential use in quantitative provenance studies. Sedimentary Geology 171(1), 37-58. 